\title{
An evaluation of Australian pharmacist's attitudes on expanding their prescribing role
}

Kreshnik Hoti, Bruce Sunderland, Jeffery Hughes, Richard Parsons

Curtin Health and Innovation Research Institute and School of Pharmacy, Curtin University of Technology,

GPO Box U1987,

Perth, WA 6845,

Australia

e-mail: kreshnik.hoti@postgrad.curtin.edu.au 


\section{ABSTRACT}

Objectives: To evaluate the views of Australian pharmacists on expanded pharmacist prescribing roles and identify important drivers and barriers to its implementation.

Setting: Pharmacists in Australia

Method: Data were collected using a self-administered questionnaire distributed nationally to a random sample of pharmacists either directly, or in the case of one state, via community pharmacies. One-way ANOVA and Chi-square testing were used to identify significant associations. Factor analysis was conducted to pool variables and the derived factors were subjected to regression analysis.

Main Outcome Measures: Perceptions of Australian pharmacists on expanded prescribing and the relationships between variables derived.

Results: A total of 2592 questionnaires were distributed and a response rate of $40.4 \%$ was achieved $(n=1049)$. Of the respondents $83.9 \%$ strongly agreed/agreed to an expanded prescribing role for pharmacists and $97.1 \%$ reported they would need further training. Of the respondents 896 agreed that pharmacists should engage in supplementary, independent prescribing or both. Of these $69.1 \%$ preferred only supplementary prescribing, $3.3 \%$ independent prescribing and $27.4 \%$ both models. Both models were found to be positive predictors of expanding pharmaceutical services through prescribing $(\mathrm{p}<0.001)$ with supplementary prescribing showing a stronger association ( $\beta=0.52$ vs. $\beta=0.18)$. Pharmacists' opinion based on their current perceptions of their clients was an important predictor in expanding pharmaceutical services through prescribing $(\mathrm{p}=0.005)$. Inadequate training in patient assessment, diagnosis and monitoring were the strongest barriers to expanded pharmacist prescribing $(\mathrm{p}<0.001)$. 
Conclusions: The majority of Australian pharmacists supported an expanded pharmacist prescribing role. Support for supplementary was stronger than independent prescribing. Pharmacists acknowledged that they would need further training to perform such roles.

\section{Impact of findings on practice}

- Australian pharmacists appreciate an expanded pharmacist prescribing role.

- Australian pharmacists prefer a role in supplementary prescribing over an independent prescribing role.

Keywords: Attitudes, Australia, Independent prescribing, Pharmacists, Pharmacist prescribing, Supplementary prescribing 


\section{Introduction}

Expanded prescribing as a specialist role for pharmacists is developing in several countries. In the United Kingdom (UK) a supplementary prescribing model including pharmacists has recently been expanded where, within specific criteria, pharmacists may prescribe independently. ${ }^{1,2}$ In the United States of America (USA) pharmacists are involved with doctors in collaborative drug therapy management. ${ }^{3}$ Major developments in pharmacist prescribing have also occurred in Canada, where Alberta implemented a three category prescribing model: ‘adapting a prescription', emergency prescribing, and initiating and managing drug therapy. ${ }^{4,5}$ Van Foppe et al. have suggested that the pharmacy profession in Europe, other than in the UK, was not at a stage where pharmacist prescribing could be implemented. ${ }^{6,7}$

In supplementary prescribing the primary prescriber diagnoses and initiates therapy whilst the supplementary prescriber continues the prescribing within the agreed management plan parameters. $^{2,8}$ In the case where pharmacists prescribe independently of medical practitioners, they assume the responsibility for clinical assessment of the patient, establishing the diagnosis and clinical management for a defined range of conditions within professional and clinical competence. ${ }^{2,9}$

Qualified pharmacist independent prescribers in the UK are able to prescribe any licensed medicine within their area of expertise except for controlled drugs. ${ }^{1,2}$ The restriction on prescribing of controlled drugs is due to change pending the amendment of legislation. ${ }^{10}$ 
Pharmacists in Australia are able to prescribe medications listed under 'Pharmacy medicines' (S2) and 'Pharmacist only medicines' (S3) schedules. These medicines are available to the public from community pharmacies. Some drugs in these categories have been "downscheduled" from "prescription only" medicines. Australian pharmacists are also able to continue the supply of prescription only medications based on 'emergency supply' and ‘repeat prescription’ systems.

The Australian Government Productivity Commission has recommended that Australia should expand the roles of other health professionals to include some current aspects of doctor's tasks. ${ }^{11}$ The Australian Medical Association (AMA) does not consider the Productivity Commission's recommendation as the best solution for addressing workforce shortages, however, the medical profession embraces the idea of allocating clinical responsibilities to other medically trained health professionals "wherever it can be done safely and effectively". ${ }^{12}$ The AMA at the same time has warned that this could lead to shortages of other healthcare professionals. In terms of expanding pharmacist prescribing specifically, the AMA has in the past signalled that it does not support such a role for pharmacists. ${ }^{13}$ The Royal Australasian College of Physicians (RACP) supports task transfer "both across its specialty groups and to other health professionals as long as this transfer is “evidence-based, safe, cost-efficient and it facilitates patient care.”14

The aims of this study were to survey Australian pharmacists for their views on supplementary and independent prescribing as expanded roles of pharmaceutical professional practice and to identify the important drivers and barriers to pharmacist prescribing in Australia. 


\section{Methods}

This study was approved by the Human Research Ethics Committee of Curtin University of Technology.

Questionnaire development

Data were collected using a standardised questionnaire (shown in the “Appendix"). The questionnaire was initially constructed based on a review of the relevant literature and findings from a focus group meeting. It was then pre-piloted on 114 Western Australian pharmacists, following which minor changes were made. The final questionnaire had nine sections related to: 1) expansion of pharmacy professional services and pharmacist prescribing, 2) pharmacists perceptions of their clients, 3) advantages of expanding the pharmacist's prescribing role 4) prescribing models preferred 5) barriers to expanded pharmacist prescribing 6) therapeutic areas in which pharmacists supported expanded prescribing 7) training requirements to prescribe 8) infrastructural implications, and 9) expansion of the current role in the management of minor ailments. Dependent upon the question, pharmacists were either asked to respond yes/no or to complete a five point Likert scale to assess their level of agreement with a particular statement. The questionnaire also contained a section gathering some basic demographic data.

The self-administered questionnaire was posted nationally to a random sample of pharmacists either directly or in the state of New South Wales (NSW) through a random sample of community pharmacies. The sample was drawn from Registers obtained from State Pharmacy Boards (South Australia, Victoria, Tasmania) and the Pharmaceutical Council of Western Australia. Registers for NSW and Queensland were not made available due to privacy issues. 
A random sample of pharmacies in NSW was chosen from those listed in the telephone directory "Yellow Pages". The sample for Queensland was drawn from the list of pharmacists made available publicly online by the Pharmacy Board of Queensland. A 20\% sample was drawn for each of the abovementioned States using an electronic randomiser. The Northern Territory (NT) and the Australian Capital Territory (ACT) were excluded due to limited numbers of potential respondents. The questionnaires were distributed by mail in December 2007 and a follow-up in January 2008 and included “replied paid” envelopes.

\section{Data analysis}

Data were coded and analysed using SPSS v16. Standard descriptive statistics were used to summarise demographic data and responses to the questionnaires (frequencies for categorical variables, and means and standard deviations for variables measured on a continuous scale). Comparisons of binary (Yes/No) variables across different geographical areas and across different practice settings were performed using Chi-square statistics. Variables measured on the Likert scale were either formed into 3 categories (agree, neutral, disagree), or treated as continuous variables. With the large sample size used in this study, the distribution of the mean score for variables based on the Likert scale can safely be assumed to be Normal (Central Limit Theorem). Analysis of Variance (ANOVA) was used to compare the means of Likert scale variables where the independent variables had more than 2 categories. For example, the influence of years since the Pharmacist's registration (divided into 4 groups: 0-5 years, 6-10 years, 11-20 years and $>20$ years) on attitudes measured on the Likert scale was analysed using ANOVA. 
On the questionnaire, sections: 1 ("Prescribing and the future of the pharmacy profession"), 2 ("Pharmacists opinions on how expanded prescribing would be received by clients"), 3 (“Pharmacists' opinions towards potential advantages of expanded prescribing”), and 5 ("Barriers to expanded prescribing”) each contained several questions. Internal consistency of the questions within each section was performed using Cronbach’s coefficient alpha. This was done to confirm that the questions within each section were measuring different facets of the same theme. In order to reduce each section to a single "score" to represent each theme, responses could have been summed within each section (giving equal weight to each question). Factor Analysis is a more rigorous method of identifying appropriate question weightings so that the weighted linear combination of responses explains as much of the variance for the section as possible. Accordingly, Factor Analysis was applied to each of these four sections in turn with the aim of obtaining a single summary score for each section for each respondent. Multiple regression analysis was then performed with the Section 1 summary score as dependent variable (renamed: "Expanded pharmaceutical services through prescribing”), so that factors associated with this variable could be identified.

\section{Results}

A total of 1049 of the 2592 questionnaires distributed were returned giving a response rate of 40.4\%. Demographic characteristics of the respondents are summarised in Table 1 . The majority of the respondents were employee community pharmacists working in larger pharmacies (annual income $\geq \mathrm{AU} \$ 2 \mathrm{M})$.

\section{[Insert table 1 here]}


Frequency distributions revealed that $83.9 \%$ of respondents reported that pharmacists should have access to expanded prescribing rights. Almost all respondents (97.1\%) reported that if they were to undertake additional prescribing responsibilities, they would need further training. Chi-square testing for these findings showed no significant differences between samples drawn from different States in relation to the above questions ( $\mathrm{p}=0.095 ; \mathrm{p}=0.293$, respectively). The first 2 questions of section 4 in the questionnaire relate to pharmacists prescribing independently or supplementary to a doctor. The response to each question was reduced to "agree/strongly agree" versus other, and respondents were identified as those who supported Supplementary alone, Independent alone, both or neither of these prescribing models. Of the 1049 respondents, 896 agreed to at least one of these models. Amongst these 896 respondents, supplementary prescribing alone was the preferred model (69.1\% strongly agreed/agreed) with far fewer supporting only an independent model (3.3\% strongly agreed/agreed). A total of 246 of respondents preferred both models (27.4\% strongly agreed/agreed). Most respondents ( $n=1019$, 74.1\%) did not agree that expanded prescribing should be limited only to hospital pharmacists. One-way ANOVA showed that there was no significant difference between pharmacists working in different settings (i.e. community, hospital, medication reviews, others) in regards to their preference for independent $(\mathrm{p}=0.115)$, or supplementary prescribing models $(\mathrm{p}=0.087)$. No significant difference was also found using one-way ANOVA between pharmacists' period of registration and their preference for the above prescribing models $(p=0.835 ; p=0.663$, respectively).

Respondents supported an expanded prescribing role as it would better use pharmacists' skills and ease the work-load burden on general medical practitioners. The majority of respondents did not regard increased government or patient cost, or reduction in the quality of patient care as significant barriers to this role. These attitudes are summarised in Table 2. 


\section{[Insert table 2 here]}

Respondents who preferred only the supplementary prescribing model, showed strongest support for expanded prescribing for asthma and a limited range of infections, followed by hypertension, pain management and diabetes. Those that favoured only the independent prescribing model showed strongest support for a limited range of infections and pain management. Respondents who supported both models showed remarkable preference consistency with those that only preferred either supplementary or independent prescribing. These indicated that pharmacists who preferred the independent prescribing model showed strongest prescribing support for the areas of a limited number of infections and pain management. On the other hand, asthma was the most preferred therapeutic area of prescribing for supporters of the supplementary prescribing model, regardless of their support for the independent model. Lower levels of support by all groups were seen for an expanded role in anticoagulation and heart failure. These preferences are summarised in Table 3.

\section{[Insert table 3 here]}

\section{Factor Analysis}

Principal Component Analysis was performed on each of sections 1, 2, 3 and 5. In each case, the Kaiser-Meyer-Olkin measure of sampling adequacy was high $(>0.6)$ and Bartlett's test of sphericity $(<0.0001)$ confirmed the suitability of these data for this type of analysis. The following factors were extracted for the groups of questions 1, 2, and 3 above: 1) Expanding pharmaceutical services through prescribing 2) Pharmacist prescribing drivers 3) Pharmacists' 
opinion based upon their perceptions of their clients. Only one factor for each of these questions was identified as having a significant contribution to the total variance for these questions (eigenvalue greater than one). For each factor extracted, the percentage of variance explained was $>58 \%$. Internal consistency using Cronbach's alpha for these groups of statements were: 1 ) 0.86, 2) 0.89 and 3) 0.82 . The factor loadings for these three factors were as follows: 1) Expanding pharmaceutical services through prescribing: $(0.77,0.93,0.88,0.79)$; 2) Pharmacist prescribing drivers: (0.82, 0.83, 0.71, 0.72, 0.75); 3) Pharmacists’ opinion based upon their perceptions of their clients: $(0.76,0.82,0.85,0.85,0.77,0.69,0.87,0)$. These loadings correspond with the questions in questionnaire sections 1,2 and 3 and are in the same order as these questions.

In factoring the group of questions in section 5 (barriers to an increased pharmacists' prescribing role), three factors emerged with eigenvalues of more than 1.0. Clearer interpretation of the factors was obtained by applying a Varimax rotation as shown in Table 4. Three factors, which explained $64.3 \%$ of the variance pertained to: i) other barriers; ii) increased cost and deterioration of patient care and iii) inadequate training in diagnosis, patient assessment and monitoring. Cronbach's alpha internal consistencies were as follows: i) other barriers 0.83 ; ii) increased cost and deterioration of patient care 0.87 and iii) inadequate training in diagnosis, patient assessment and monitoring 0.83 . Note that the final question for this section ("None of the above”) was excluded from this analysis.

\section{[Insert table 4 here]}




\section{Regression analysis}

Two regression analyses were performed, both of them using the factor summary score obtained from section 1 as the dependent variable ("Expanding pharmaceutical professional services”). The first examined the data for any association with independent and supplementary prescribing. This model explained 36.7\% variance. Both independent and supplementary prescribing were positive predictors of expanding pharmaceutical services through prescribing $(p<0.001)$. Pharmacists who preferred supplementary prescribing showed a stronger association (based on the regression coefficient, $\beta$ ) compared to pharmacists who preferred independent prescribing ( $\beta$ $=0.52$ vs. $\beta=0.18)$.

In the second regression model, the independent variables included the five summary scores found through the factor analyses performed on sections 2,3 and 5. This model explained 62.2\% of variance. The results of this model, shown in Table 5, indicated that both pharmacist prescribing drivers (i.e. advantages) and their opinions based upon their experience with clients were important positive predictors of an expansion of pharmacist services through prescribing ( $p<0.001$ and $p=0.005 ; \beta=0.74$ and $\beta=0.12$, respectively). The model also showed patient diagnosis, assessment and monitoring were more negatively associated with expanding services through prescribing as opposed to other barriers (i.e. disadvantages) or increased cost and deterioration of patient care $(p<0.001, p=0.003 \& p=0.004 ; \beta=-0.098, \beta=-0.091 \& \beta=-0.075)$, respectively. The above findings are summarised in Figure 1, which encapsulates the factors and weightings that had significant positive and negative impact on pharmacists considering moving towards an expanded prescribing role.

\section{[Insert table 5 here]}




\section{[Insert figure 1 here]}

\section{Discussion}

To our knowledge this is the first major study on the attitudes of Australian pharmacists to pharmacist prescribing. This study has examined the views of a large sample of Australian pharmacists on pharmacist prescribing from all areas of pharmacy practice and all Australian states. Respondent pharmacists' place of practice in this study was reflective of the Australian Bureau of Statistics (ABS) Population Census data 2006 (i.e. Community pharmacists $84.9 \%$, Hospital $11.2 \%$ and Industrial $3.8 \%$ ). ${ }^{15}$ A response rate of $40.4 \%$, although adequate for a postal survey, leaves a possibility of some non-respondents not sharing the same views as respondents. However, the respondents' highly supportive views for expanded pharmacist prescribing (83.9\%) suggests that non-respondents' views would not markedly influence the findings.

Pharmacists who participated in this study were clearly in favour of expanding the scope of pharmaceutical services through expanding their prescribing role, although they believed further training was needed to assume such a role. Australian pharmacists preferred a supplementary prescribing model. The current strong support for the supplementary model might suggest this model should be initially introduced. The level of support for independent prescribing in this study was less than reported in a previous Australian study. ${ }^{16}$ However, that study was limited by a low response rate (6.4\%) and an under-representation of

community pharmacists. ${ }^{16}$ Although in this study both supplementary and independent prescribing were positive predictors of expanding pharmaceutical services through prescribing, pharmacists who were in favour of supplementary prescribing showed a stronger 
association towards this expansion. It is worth emphasising that pharmacists' opinions based upon their perceptions of their clients was shown to be an important predictor of expanding pharmaceutical services through prescribing. To date there is a lack of literature exploring this particular relationship. Respondents who favoured the independent model showed support for less therapeutic areas of prescribing compared to supporters of supplementary prescribing. This was probably because supplementary prescribing does not involve the initial diagnosis and prescribing.

The positive attitude towards a supplementary prescribing model found in this study is supported by the views of pharmacists reported elsewhere. A survey conducted in the UK by Hobson and Sewell ${ }^{6}$, suggested that despite concerns, pharmacists had a positive attitude towards supplementary prescribing and that pharmacists in the UK wished to assume this role. The main reasons for Australian pharmacists supporting an expanded role in prescribing were: better use of pharmacists' skills, easing the burden from overloaded general practitioners and pharmacists’ drug knowledge. In several 'Crown Reports’, a greater use of pharmacist skills in order to develop a more flexible system of prescribing, administration and supply of medicines was identified as the main driver for expanding pharmacist prescribing in the UK. ${ }^{9,17}$ In addition, England's Department of Health identified improvement of patient care, medication access and team work within the healthcare system as the main aims for introducing independent pharmacist prescribing. ${ }^{2}$

The major concerns identified by respondents in this study for expanded pharmacist prescribing were inadequate training in patient assessment, diagnosis and monitoring. These concerns were also found to be the strongest negative predictors of expanding pharmacists' prescribing role in Australia. Early experience from supplementary prescribers in the UK has 
suggested inadequate funding to be a major limitation for delivering this service. ${ }^{18}$ Review of the literature revealed a variety of other limitations including potential conflict with doctors, need for greater liability insurance, excessive workload and time pressures. ${ }^{19-22}$ A possibility for fragmentation of care resulting in increased costs and inefficiencies within the health care system has also been reported. ${ }^{9}$ Conflict of interest with pharmacists having a commercial interest in prescribing with supply and inadequate access to patient records were also reported to be obstacles towards the adoption of this role. ${ }^{22,23}$

The health system in Australia is under stress from factors such as the ageing population, increased morbidity, increased chronic diseases and insufficient doctors to keep pace with population growth. ${ }^{24}$ Insufficient numbers of health professionals is driving task transfer. ${ }^{12}$ There are indications that fewer medical graduates are choosing general practice as a career, hence adding to the existing general practitioner shortage. ${ }^{25}$ Furthermore, Joyce et al. $^{26}$ predicted a continued shortage of general practitioners in Australia, hence suggesting that innovative primary medical care policies were necessary. This needs to be weighed against international experience with the established supplementary prescribing model in the UK showing benefits for both patients and pharmacists. These benefits have included: improved patient management, job satisfaction for pharmacists and greater patient satisfaction. ${ }^{18} \mathrm{~A}$ qualitative study conducted in Australia by Bessell et al. ${ }^{27}$ proposed four practice models where pharmacists could initiate, modify and monitor access and use of prescription medicines. According to this study, these models provided consumers with improved, responsible and safe access to prescription medicines. Other studies, although limited in representativeness also confirmed that an expanded role in prescribing was supported by Australian pharmacists. ${ }^{18,28}$ 
Results of this study identify strong pharmacist support for constructing policies and recommendations towards future pharmacist prescribing in Australia. They are also valuable elsewhere, given the global interest on this issue and the lack of literature exploring pharmacists' views outside of the UK. ${ }^{17,19,29}$

\section{Conclusion}

Australian pharmacists strongly supported an expanded pharmacist prescribing role, despite perceived barriers. Their preference was for a supplementary over an independent prescribing model, with support of this model being a strong predictor of pharmacists expanding their pharmaceutical services through prescribing. A significant driver for expanding the pharmacist's prescribing role was the pharmacists' opinion based on their current perceptions of their clients. Important barriers included inadequate skills in patient assessment, diagnosis and monitoring. This study provides evidence to regulatory bodies that a move towards an expanded pharmacist prescribing would be well supported by the profession.

\section{Acknowledgements}

The authors wish to acknowledge the contribution of pharmacists that participated in this study and statistical support provided by Jennifer Lalor and Associate Professor Satvinder Dhaliwal of Curtin University of Technology. 


\section{Conflict of Interest}

None

\section{Financial support}

This research was entirely funded by Curtin University of Technology, School of Pharmacy.

\section{References}

1. Department of Health; Pharmacist Independent Prescribing; London, UK; March 2007; [online]:

http://www.dh.gov.uk/en/Healthcare/Medicinespharmacyandindustry/Prescriptions/TheNonMedicalPrescribingProgramme/Independentpharmacistprescribing/DH_4133943 (Accessed 29 April 2009)

2. Department of Health; Improving patients' access to medicines: A guide to implementing nurse and pharmacist independent prescribing within the NHS in England ; April 2006; [online] http://www.dh.gov.uk/en/Publicationsandstatistics/Publications/PublicationsPolicyAndGuida nce/DH_4133743 (Accessed 28 April 2009)

3. Zellmer W. Collaborative drug therapy management. Am J Health Syst Pharm. 1995;52:1732. 
4. Pearson G. Evolution in the practice of pharmacy-not a revolution. CMAJ. 2007; 176: 1295-6.

5. Yuksel N, Eberhart G, Bungard TJ. Prescribing by pharmacists in Alberta. Am J Health Syst Pharm. 2008; 65:2126-32.

6. Hobson R, Sewell G. Risks and concerns about supplementary prescribing: survey of primary and secondary care pharmacists. Pharm World Sci. 2006; 28: 76-90.

7. Van Foppe MJ, Schultz M, Tromp TF. Pharmaceutical care, European developments in concepts, implementation, teaching and research: a review. Pharm World Sci. 2004; 26: 303-11.

8. Kidd M, Watts I, Mitchell C. Principles for supporting task substitution in Australian general practice. Med J Aust 2006; 185: 20-2.

9. Crown J (1999) Review of prescribing, supply and administration of medicines. Final report. London, Department of Health. [online] www.dh.gov.uk/en/Publicationsandstatistics/Publications/PublicationsPolicyandGuidance/D H_4077151 (Accessed 26 March 2009) 
10. Royal Pharmaceutical Society of Great Britain, Prescribing of Controlled Drugs by pharmacist and nurse independent prescribers, Law and Ethics Bulletin, London, UK, [online] www.rpsgb.org.uk/pdfs/LEBprescontrolledrugs.pdf (Accessed 30 October 2009)

11. The Australian Government Productivity Commission. Australia's health workforce. Productivity Commission research report, 22 December 2005. Canberra. Productivity Commission,2005.[online] http://www.pc.gov.au/_data/assets/pdf_file/0003/9480/healthworkforce.pdf. (Accessed 25 May 2009)

12. Yong C. Task substitution: the view of the Australian Medical Association. Med $J$ Aust. 2006; 185: 27-8.

13 The Australian Medical Association; Patient safety paramount in medication prescriptions, 2008 Media Releases, [online] http://www.ama.com.au/node/3358 (Accessed 30 May 2009)

14. Sewell J. Task transfer: The view of the Royal Australasian College of Physicians. Med J Aust. 2006; 185: 23-4.

15. Australian Bureau of Statistics (ABS) 2008; 2006 Census of Population and Housing; Canberra; [online] http://www.censusdata.abs.gov.au/ (Accessed 12 January 2009) 
16. Kay OC, Bajorek BV, Brien JA. Pharmacist Prescribing Activities-an electronic survey on the opinions of Australian pharmacists. J Pharm Pract Res. 2006; 36(3):199-203

17. Tonna AP, Stewart D, West D, McCaig D. Pharmacist prescribing in the UK; a lit erature review of current practice and research. J Clin Pharm Ther. 2007; 32: 545-56.

18. George J, McCaig D, Bond CM et al. Supplementary prescribing: early experiences of pharmacists in the UK. Ann Pharmacother. 2006; 40(10):1843-50.

19. Kay OC; Brien JE. Pharmacist Prescribing: Review of the literature. J Pharm Pract Res. 2004; 34(4): 300-4.

20. $\quad$ Eng HJ. The pharmacist as prescriber; J Clin Pharm Ther. 1987; 12: 237-42.

21. Segal R; Grines LL. Prescribing authority for pharmacists as viewed by organized pharmacy, organized medicine, and the pharmaceutical industry; Drug Intel Clin Pharm. 1988; 22: 241-6.

22. Bellingham C. Space, time and team working: issues for pharmacists who wish to prescribe. Pharm J. 2002; 268: 562-4.

23. Stimmel GL. Political and legal aspects of pharmacist prescribing; Am J Hosp Pharm. 1983; 40:1343-4. 
24. Del Mar C; Dwyer N. A radical new treatment for the sick health workforce; Med J Aust . 2006; 185: 32-4.

25. Joyce C; McNeill J. Fewer medical graduates are choosing general practice: a comparison of four cohorts, 1980-1995. Med J Aust. 2006; 185: 102-4.

26. Joyce C, McNeil A, Stoelwinder J. More doctors, but not enough: Australian medical workforce supply 2001-2012. Med J Aust. 2006; 184: 441-446.

27. Bessell T, Emmerton L, Marriot J, Nissen L. Improving Australians’access to prescription medicines: proposed practice models; June 2005; Pharmacy Guild of Australia; Canberra;[online] http://www.guild.org.au/uploadedfiles/Research_and_Development_Grants_Program/Project s/2003-017_fr.pdf. (Accessed 22 March 2009)

28. Hanes CA, Bajorek BV. Pharmacist Prescribing: Views of Australian Hospital Pharmacists. J Pharm Pract Res. 2005; 35(3):178-80.

29 Emmerton L, Marriot J, Bessell T, et al. Pharmacists and Prescribing Rights: Review of International Developments. J Pharm Pharm Sci. 2005; 8: 217-25. 
Table 1 Demographic characteristics of respondents $\left(n=1049^{a}\right)$

\begin{tabular}{|c|c|c|}
\hline Variable & Category & n (\%) \\
\hline \multirow[t]{2}{*}{ Gender } & Male & $536(51.6)$ \\
\hline & Female & $503(48.4)$ \\
\hline Mean age (SD) & & 42.8 years $(\mathrm{SD}=13.5)$ \\
\hline $\begin{array}{l}\text { Mean years (SD) of registration as } \\
\text { pharmacist }\end{array}$ & & 20.5 years $(\mathrm{SD}=14.2)$ \\
\hline \multirow{4}{*}{ Practice setting } & Community & $873(84.1)$ \\
\hline & Hospital & $119(11.5)$ \\
\hline & Medication reviews (i.e. consultant pharmacists) & $14(1.3)$ \\
\hline & Other & $32(3.1)$ \\
\hline \multirow[t]{2}{*}{ Pharmacy ownership } & Owners & $\begin{array}{l}359 \text { ( } 41.1 \% \text { of community } \\
\text { pharmacists) }\end{array}$ \\
\hline & Non-owners & $\begin{array}{l}675 \quad(65.3 \% \text { of } \\
\text { pharmacists })\end{array}$ \\
\hline \multirow{6}{*}{ Australian places of practice } & Victoria & $422(40.9)$ \\
\hline & New South Wales & 199 (19.3) \\
\hline & Queensland & $88(8.5)$ \\
\hline & Western Australia & $156(15.1)$ \\
\hline & South Australia & $121(11.7)$ \\
\hline & Tasmania & $43(4.2)$ \\
\hline
\end{tabular}

${ }^{\mathrm{a}}$ For each category there were some missing responses 
Table 2 A summary of attitudes related to expanded pharmacist prescribing $\left(n=1049^{a}\right)$

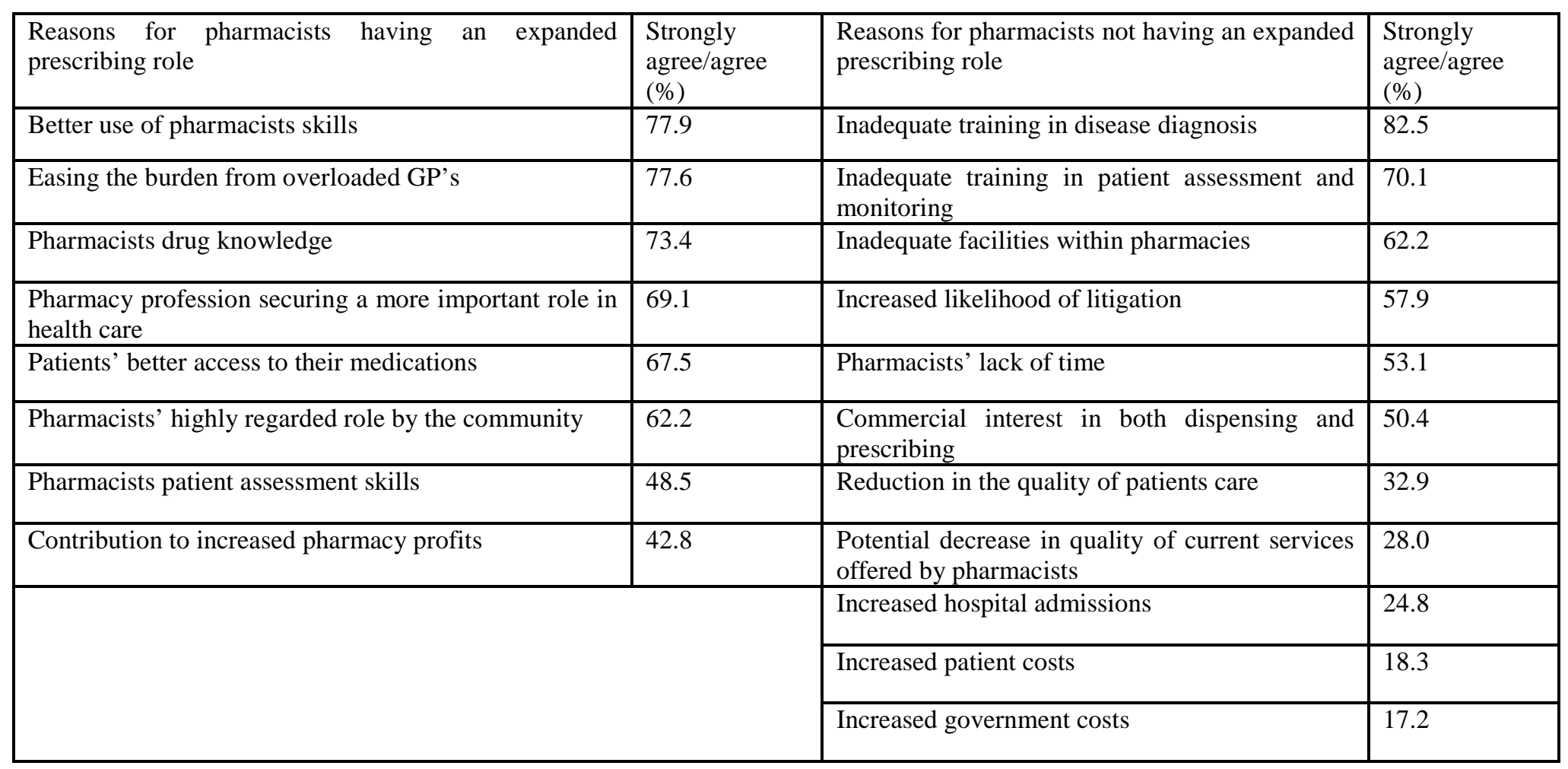

${ }^{\mathrm{a}}$ For each statement there were some missing responses 
Table 3 Respondents level of support for therapeutic areas of pharmacist prescribing

\begin{tabular}{|c|c|c|c|c|c|c|c|c|c|c|c|c|}
\hline & \multirow{2}{*}{\multicolumn{3}{|c|}{$\begin{array}{l}\text { Supporters of } \\
\text { supplementary model } \\
\text { only } \\
(\mathrm{n}=516, \\
\left.104 \text { missing }{ }^{\mathrm{a}}\right)\end{array}$}} & \multirow{2}{*}{\multicolumn{3}{|c|}{$\begin{array}{l}\text { Supporters of } \\
\text { independent } \\
\text { model only } \\
\text { (n=28, } 2 \text { missing) }\end{array}$}} & \multicolumn{6}{|c|}{$\begin{array}{l}\text { Supporters of both supplementary and independents } \\
\text { prescribing models } \\
\text { (n=208, } 38 \text { missing) }\end{array}$} \\
\hline & & & & & & & \multicolumn{3}{|c|}{ Independent model } & \multicolumn{3}{|c|}{ Supplementary model } \\
\hline & $\begin{array}{c}\text { A/SA } \\
(\%)\end{array}$ & $\begin{array}{c}\mathrm{N} \\
(\%)\end{array}$ & $\begin{array}{c}\mathrm{D} / \mathrm{SD} \\
(\%)\end{array}$ & $\begin{array}{c}\text { A/SA } \\
(\%)\end{array}$ & $\begin{array}{c}\mathrm{N} \\
(\%)\end{array}$ & $\begin{array}{c}\mathrm{D} / \mathrm{SD} \\
(\%)\end{array}$ & $\begin{array}{c}\text { A/SA } \\
(\%)\end{array}$ & $\begin{array}{c}\mathrm{N} \\
(\%)\end{array}$ & $\begin{array}{l}\mathrm{D} / \mathrm{SD} \\
(\%)\end{array}$ & $\begin{array}{c}\mathrm{A} / \mathrm{SA} * \\
(\%)\end{array}$ & $\begin{array}{c}\mathrm{N} \\
(\%)\end{array}$ & $\begin{array}{c}\mathrm{D} / \mathrm{SD} \\
(\%)\end{array}$ \\
\hline Antibiotics $^{b}$ & 79.1 & 6.4 & 14.6 & 82.1 & 7.1 & 10.7 & 78.3 & 6.6 & 15.1 & 75.4 & 6.3 & 18.3 \\
\hline Diabetes & 73.4 & 11.8 & 14.7 & 46.4 & 28.6 & 25.0 & 45.1 & 10.8 & 44.1 & 77.9 & 7.2 & 14.9 \\
\hline Hypertension & 76.5 & 8.9 & 14.5 & 46.5 & 10.7 & 42.8 & 45.1 & 12.3 & 42.7 & 75.0 & 9.6 & 15.4 \\
\hline Heart Failure & 43.5 & 16.9 & 39.6 & 28.6 & 17.9 & 53.5 & 21.1 & 17.2 & 61.8 & 49.7 & 18.0 & 32.2 \\
\hline Asthma & 86.6 & 6.0 & 7.4 & 67.9 & 10.7 & 21.4 & 72.0 & 11.0 & 17.2 & 80.8 & 3.8 & 15.4 \\
\hline Anticoagulation & 55.6 & 13.4 & 31.0 & 46.4 & 14.3 & 39.3 & 29.4 & 15.7 & 54.9 & 59.3 & 13.9 & 26.8 \\
\hline Pain management & 75.9 & 10.7 & 13.4 & 82.1 & 10.7 & 7.2 & 74.0 & 8.5 & 17.5 & 73.2 & 8.1 & 18.7 \\
\hline
\end{tabular}

A/SA=Agree/Strongly agree; $\mathrm{N}=$ neutral; $\mathrm{D} / \mathrm{SD}=$ Disagree/Strongly disagree

a Missing is from the data set for these questions

b Treatment of a limited number of infections 
Table 4 Rotated component matrix data for limitations of an expanded prescribing role by pharmacists

\begin{tabular}{|c|c|c|c|}
\hline \multirow[b]{2}{*}{ Reasons for which pharmacists should not have expanded prescribing rights } & \multicolumn{3}{|c|}{ Factors extracted $^{(\mathrm{a})}$} \\
\hline & $\mathrm{i}$ & ii & iii \\
\hline Increased confusion amongst the public as to the roles of GP's and pharmacists & 0.752 & & \\
\hline Pharmacists' having commercial interest in prescribing & 0.727 & & \\
\hline Pharmacists' lack of time & 0.716 & & \\
\hline Potential decrease in quality of current services offered by pharmacists & 0.663 & & \\
\hline Increased likelihood of litigation & 0.662 & & \\
\hline Inadequate facilities within pharmacies to allow pharmacist prescribing & 0.659 & & \\
\hline Conflict of interest with pharmacists acting both as prescribers and dispensers & 0.642 & & \\
\hline Potential for increased hospital admissions & & 0.854 & \\
\hline Potential for increased patient costs & & 0.824 & \\
\hline Potential for increased government costs & & 0.816 & \\
\hline Potential for a reduction in the quality of patient care & & 0.731 & \\
\hline Inadequate training in patient diagnosis & & & 0.896 \\
\hline Inadequate training in patient assessment and monitoring & & & 0.864 \\
\hline
\end{tabular}

Extraction Method: Principal Component Analysis.

Rotation Method: Varimax with Kaiser Normalization. Rotation converged in 5 iterations

${ }^{a}$ factors: i) others; ii) increased cost and deterioration of patient care and iii) inadequate training in diagnosis and patient assessment 
Table $5 \beta$ values for model 2: The relationship between the variables of pharmacist prescribing drivers, barriers and pharmacists opinions based upon their experience with clients against expanding pharmaceutical services through prescribing.

\begin{tabular}{|l|r|r|r|}
\hline & \multicolumn{2}{|c|}{ Standardized coefficients $^{\mathrm{a}}$} & \multicolumn{2}{c|}{ Probability $^{*} \mathrm{t}$} \\
\hline (Constant) & \multicolumn{1}{|c|}{$\mathrm{t}$} & 6.820 & $<0.001$ \\
\hline Prescribing drivers & 1.432 & 18.847 & $<0.001$ \\
\hline Experience with clients & 0.747 & 2.796 & 0.005 \\
\hline Diagnosis and Assessment & 0.127 & -4.094 & $<0.001$ \\
\hline Cost \& deterioration of patient care & -0.098 & -2.913 & 0.004 \\
\hline Other barriers & -0.091 & -3.002 & 0.003 \\
\hline
\end{tabular}

Dependent variable: expanding pharmaceutical services through prescribing

${ }^{a}$ Negative coefficients indicate a significant barrier 


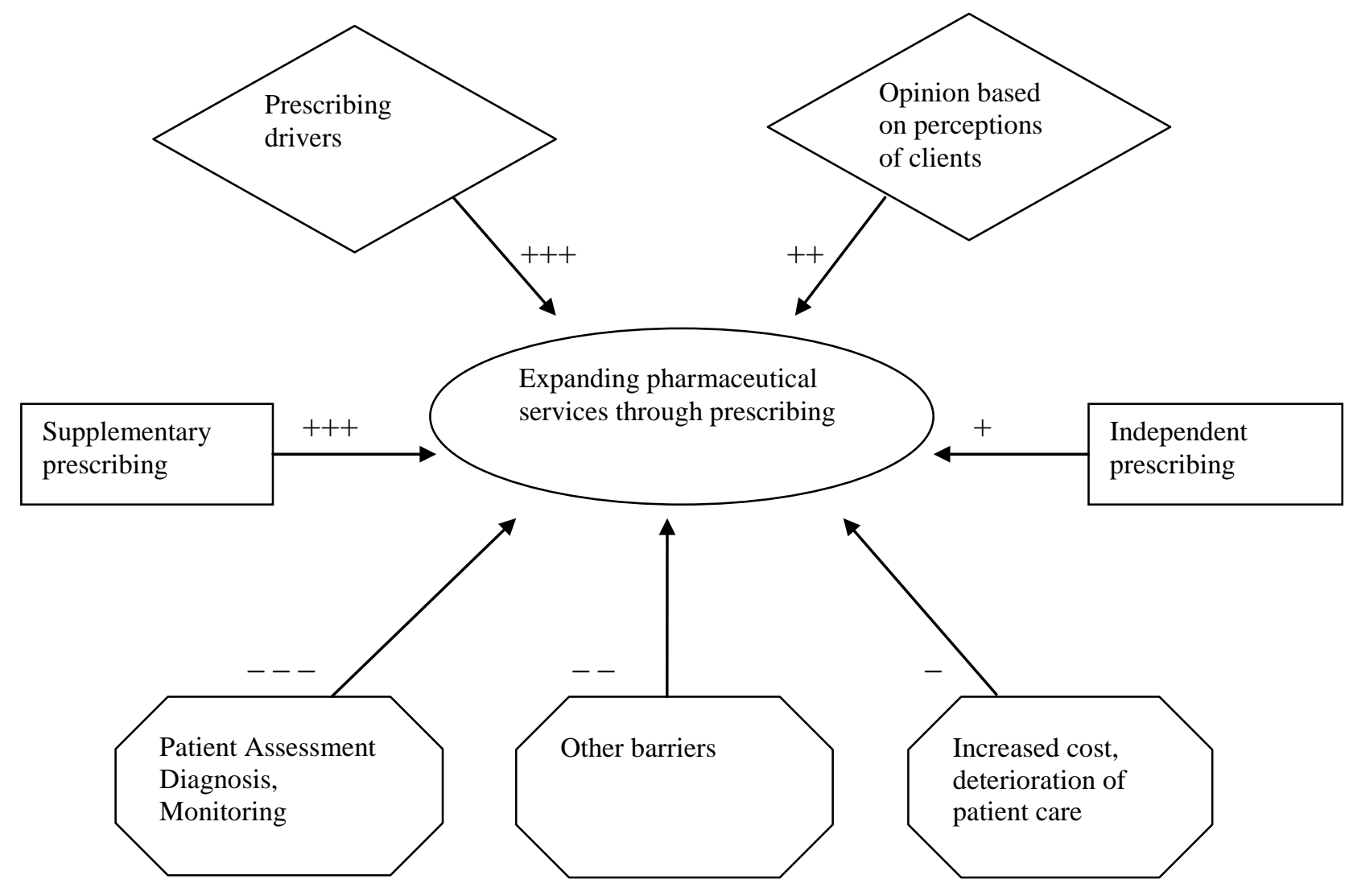

Fig. 1 Graphical illustration of a relationship model between positive and negative predictors of expanding pharmaceutical services through prescribing 


\section{APPENDIX - QUESTIONNAIRE FOR PHARMACIST PRESCRIBING IN AUSTRALIA}

The aim of this project is to assess Australian pharmacists' perceptions on the issue of extended pharmacist prescribing. In particular, we are interested in investigating their views on advantages and limitations of such a role as well as areas pharmacists feel they should have extended prescribing responsibilities, if any. Pharmacists' views are being sought on what additional training they would require in order to assume future prescribing responsibilities.

This questionnaire consists of statements and questions which enable you to give your opinion on the issue of pharmacist prescribing. It is estimated it will take you approximately 10-15 minutes to complete this questionnaire. Your information will be treated with strictest confidence.

To answer this questionnaire please TICK THE BOX NEXT TO THE NUMBER that reflects your opinion regarding the statement i.e.: 1 = Strongly disagree; 2 = Disagree; 3 = Neutral; 4 = Agree; 5 = Strongly agree. (Some questions require writing the response in the area provided)

1)

In relation to the way you see the future of the Pharmacy profession, please answer the following:

\begin{tabular}{|l|l|l|l|l|l|}
\hline I would like the Pharmacy profession to expand its scope of professional services & $1 \square$ & $2 \square$ & $3 \square$ & $4 \square$ & $5 \square$ \\
\hline I would like the Pharmacy profession to expand its scope of services, by expanding the prescribing role & $1 \square$ & $2 \square$ & $3 \square$ & $4 \square$ & $5 \square$ \\
\hline I see myself in future as having more expanded prescribing responsibilities & $1 \square$ & $2 \square$ & $3 \square$ & $4 \square$ & $5 \square$ \\
\hline I am happy with the current pharmacist's prescribing role limited to S3's & $1 \square$ & $2 \square$ & $3 \square$ & $4 \square$ & $5 \square$ \\
\hline
\end{tabular}

1= strongly disagree; $2=$ disagree; $3=$ neutral; $4=$ agree; $5=$ strongly agree

2)

Based on your experience with customers in the Pharmacy, please answer the following considering how they would react to expanded Pharmacist prescribing:

\begin{tabular}{|l|l|l|l|l|l|}
\hline Customers would accept pharmacists with an expanded prescribing role & $1 \square$ & $2 \square$ & $3 \square$ & $4 \square$ & $5 \square$ \\
\hline Customers would trust pharmacists as prescribers & $1 \square$ & $2 \square$ & $3 \square$ & $4 \square$ & $5 \square$ \\
\hline Customers would have safer access to their medications if pharmacists were prescribers & $1 \square$ & $2 \square$ & $3 \square$ & $4 \square$ & $5 \square$ \\
\hline Customers find accessing their GP's too difficult and may prefer Pharmacists having an expanded prescribing role & $1 \square$ & $2 \square$ & $3 \square$ & $4 \square$ & $5 \square$ \\
\hline Customers appreciate pharmacist 's professional advice and may prefer pharmacists as prescribers & $1 \square$ & $2 \square$ & $3 \square$ & $4 \square$ & $5 \square$ \\
\hline
\end{tabular}

3)

In relation to reasons for pharmacist prescribing, please answer the following:

\begin{tabular}{|l|l|l|l|l|l|}
\hline I believe customers would have better access to their medications if pharmacists were prescribers & $1 \square$ & $2 \square$ & $3 \square$ & $4 \square$ & $5 \square$ \\
\hline $\begin{array}{l}\text { Expanded pharmacist prescribing would ease the burden from overloaded GP's and hence improve } \\
\text { the functioning of our health system }\end{array}$ & $1 \square$ & $2 \square$ & $3 \square$ & $4 \square$ & $5 \square$ \\
\hline $\begin{array}{l}\text { Expanded prescribing responsibilities is a direction that the Pharmacy profession should be headed in } \\
\text { order to secure a more important role in health care }\end{array}$ & $1 \square$ & $2 \square$ & $3 \square$ & $4 \square$ & $5 \square$ \\
\hline Pharmacists are highly regarded by the community and therefore they should assume more prescribing responsibilities & $1 \square$ & $2 \square$ & $3 \square$ & $4 \square$ & $5 \square$ \\
\hline Pharmacists have the necessary drug knowledge to assume more prescribing responsibilities & $1 \square$ & $2 \square$ & $3 \square$ & $4 \square$ & $5 \square$ \\
\hline Pharmacists have the necessary patient assessment skills to assume more prescribing responsibilities & $1 \square$ & $2 \square$ & $3 \square$ & $4 \square$ & $5 \square$ \\
\hline Pharmacist prescribing enables better use of pharmacist's professional skills & $1 \square$ & $2 \square$ & $3 \square$ & $4 \square$ & $5 \square$ \\
\hline Expanded prescribing will contribute to increased Pharmacy profits & $1 \square$ & $2 \square$ & $3 \square$ & $4 \square$ & $5 \square$ \\
\hline
\end{tabular}

$1=$ strongly disagree; $2=$ disagree; $3=$ neutral; $4=$ agree; $5=$ strongly agree 

following:

In relation to the way you believe pharmacists should assume expanded prescribing responsibilities, please answer the

Pharmacists should be able to prescribe independent of medical practitioners, this includes assuming the responsibility of clinical assessment of the patient, establishing diagnosis and clinical management for a range of conditions within professional and clinical competence.

Pharmacists should be able to prescribe in a supplementary fashion through a partnership with an independent prescriber (a doctor or dentist) implementing an agreed patient-specific management plan. In this model the doctor diagnoses and initiates therapy while the pharmacist continues prescribing as long as patient's condition is within agreed management plan parameters.

Pharmacists should be able to prescribe from a limited drug formulary which would include current S2's, S3's and additional drugs depending on pharmacists field of specialization

Pharmacists should be able to prescribe for 30 day emergency supply, rather than current 3 day limit I believe any possible future expanded prescribing should be done by Hospital Pharmacists only

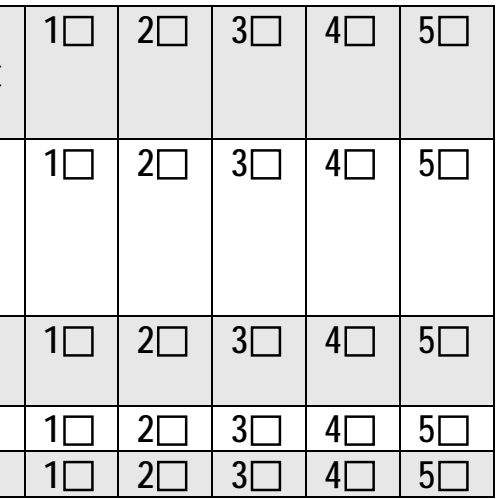
$1=$ strongly disagree; $2=$ disagree; $3=$ neutral; $4=$ agree; $5=$ strongly agree

5)

For which of the following reasons do you believe pharmacists SHOULD NOT have expanded prescribing rights?

\begin{tabular}{|c|c|c|c|c|c|}
\hline Inadequate training in diagnosis of disease (if this were the pharmacist's responsibility) & $1 \square$ & $2 \square$ & $3 \square$ & $4 \square$ & $5 \square$ \\
\hline Inadequate training in patient assessment and patient monitoring & $1 \square$ & $2 \square$ & $3 \square$ & $4 \square$ & $5 \square$ \\
\hline Potential for a reduction in the quality of patient care & $1 \square$ & $2 \square$ & $3 \square$ & $4 \square$ & $5 \square$ \\
\hline Potential for increased patient costs & $1 \square$ & $2 \square$ & $3 \square$ & $4 \square$ & $5 \square$ \\
\hline Potential for increased hospital admissions & $1 \square$ & $2 \square$ & $3 \square$ & $4 \square$ & $5 \square$ \\
\hline Potential for increased government costs & $1 \square$ & $2 \square$ & $3 \square$ & $4 \square$ & $5 \square$ \\
\hline Conflict of interest with pharmacists acting both as prescribers and dispensers & $1 \square$ & $2 \square$ & $3 \square$ & $4 \square$ & $5 \square$ \\
\hline Pharmacists' lack of time & $1 \square$ & $2 \square$ & $3 \square$ & $4 \square$ & $5 \square$ \\
\hline Increased confusion amongst the public as to the role of GP's and pharmacists & $1 \square$ & $2 \square$ & $3 \square$ & $4 \square$ & $5 \square$ \\
\hline Potential decrease in quality of current services offered by pharmacists & $1 \square$ & $2 \square$ & $3 \square$ & $4 \square$ & $5 \square$ \\
\hline Pharmacists having commercial interest in prescribing & $1 \square$ & $2 \square$ & $3 \square$ & $4 \square$ & $5 \square$ \\
\hline Inadequate facilities within pharmacies to allow pharmacist prescribing & $1 \square$ & $2 \square$ & $3 \square$ & $4 \square$ & $5 \square$ \\
\hline Increased likelihood of litigation & $1 \square$ & $2 \square$ & $3 \square$ & $4 \square$ & $5 \square$ \\
\hline None of the above & $1 \square$ & $2 \square$ & $3 \square$ & $4 \square$ & $5 \square$ \\
\hline
\end{tabular}

1= strongly disagree; $2=$ disagree; $3=$ neutral; $4=$ agree; $5=$ strongly agree

a) Do you think pharmacists should have expanded prescribing rights?

Yes

No

If answered NO please go to QUESTION 7

b) Would you wish to take on an expanded role in prescribing?

Yes

No

6)

A) Please answer the question below if you consider that pharmacists should only have an expanded prescribing role in partnership with an independent prescriber (e.g. doctor) for any of the following chronic conditions.

\begin{tabular}{|l|l|l|l|l|l|}
\hline Antibiotics (limited number of infections) & $1 \square$ & $2 \square$ & $3 \square$ & $4 \square$ & $5 \square$ \\
\hline Diabetes & $1 \square$ & $2 \square$ & $3 \square$ & $4 \square$ & $5 \square$ \\
\hline Hypertension & $1 \square$ & $2 \square$ & $3 \square$ & $4 \square$ & $5 \square$ \\
\hline Heart failure & $1 \square$ & $2 \square$ & $3 \square$ & $4 \square$ & $5 \square$ \\
\hline Asthma and other respiratory conditions & $1 \square$ & $2 \square$ & $3 \square$ & $4 \square$ & $5 \square$ \\
\hline Anticoagulant therapies & $1 \square$ & $2 \square$ & $3 \square$ & $4 \square$ & $5 \square$ \\
\hline Pain management & $1 \square$ & $2 \square$ & $3 \square$ & $4 \square$ & $5 \square$ \\
\hline All of the above & $1 \square$ & $2 \square$ & $3 \square$ & $4 \square$ & $5 \square$ \\
\hline
\end{tabular}


B) Please answer the question below if you consider that pharmacists should have an independent prescribing role for any of the following chronic conditions.

\begin{tabular}{|l|l|l|l|l|l|}
\hline Antibiotics (limited number of infections) & $1 \square$ & $2 \square$ & $3 \square$ & $4 \square$ & $5 \square$ \\
\hline Diabetes & $1 \square$ & $2 \square$ & $3 \square$ & $4 \square$ & $5 \square$ \\
\hline Hypertension & $1 \square$ & $2 \square$ & $3 \square$ & $4 \square$ & $5 \square$ \\
\hline Heart failure & $1 \square$ & $2 \square$ & $3 \square$ & $4 \square$ & $5 \square$ \\
\hline Asthma and other respiratory conditions & $1 \square$ & $2 \square$ & $3 \square$ & $4 \square$ & $5 \square$ \\
\hline Anticoagulant therapies & $1 \square$ & $2 \square$ & $3 \square$ & $4 \square$ & $5 \square$ \\
\hline Pain management & $1 \square$ & $2 \square$ & $3 \square$ & $4 \square$ & $5 \square$ \\
\hline All of the above & $1 \square$ & $2 \square$ & $3 \square$ & $4 \square$ & $5 \square$ \\
\hline
\end{tabular}

7)

If I was about to assume additional prescribing responsibilities, I would need further training: Yes $\square \quad$ No $\square$ If NO please go straight to question 8.

A) In order to assume expanded prescribing responsibilities I would need further training in the following therapeutic areas:

\begin{tabular}{|l|l|l|l|l|l|}
\hline Clinical pharmacology & $1 \square$ & $2 \square$ & $3 \square$ & $4 \square$ & $5 \square$ \\
\hline Pharmacodynamics and pharmacokinetics & $1 \square$ & $2 \square$ & $3 \square$ & $4 \square$ & $5 \square$ \\
\hline Adverse drug reactions and drug interactions & $1 \square$ & $2 \square$ & $3 \square$ & $4 \square$ & $5 \square$ \\
\hline Pathophysiology of conditions that you would prescribe for & $1 \square$ & $2 \square$ & $3 \square$ & $4 \square$ & $5 \square$ \\
\hline Selection of drug regimen & $1 \square$ & $2 \square$ & $3 \square$ & $4 \square$ & $5 \square$ \\
\hline Physiological changes and drug response in different age groups & $1 \square$ & $2 \square$ & $3 \square$ & $4 \square$ & $5 \square$ \\
\hline
\end{tabular}

B) In order to assume expanded prescribing responsibilities I would need further training in the following areas:

\begin{tabular}{|l|l|l|l|l|l|}
\hline Patient consultation and decision making & $1 \square$ & $2 \square$ & $3 \square$ & $4 \square$ & $5 \square$ \\
\hline Communication skills & $1 \square$ & $2 \square$ & $3 \square$ & $4 \square$ & $5 \square$ \\
\hline Principles of diagnosis & $1 \square$ & $2 \square$ & $3 \square$ & $4 \square$ & $5 \square$ \\
\hline Evidence based practice & $1 \square$ & $2 \square$ & $3 \square$ & $4 \square$ & $5 \square$ \\
\hline Legal and ethical aspects of prescribing & $1 \square$ & $2 \square$ & $3 \square$ & $4 \square$ & $5 \square$ \\
\hline Psychology of prescribing & $1 \square$ & $2 \square$ & $3 \square$ & $4 \square$ & $5 \square$ \\
\hline Principles and methods of patient monitoring (physical examination, laboratory results, patient compliance) & $1 \square$ & $2 \square$ & $3 \square$ & $4 \square$ & $5 \square$ \\
\hline Public health issues & $1 \square$ & $2 \square$ & $3 \square$ & $4 \square$ & $5 \square$ \\
\hline
\end{tabular}

C) In order to assume expanded prescribing responsibilities pharmacist prescribers would need:

\begin{tabular}{|l|l|l|l|l|l|}
\hline A period of supervision by a Medical Practitioner & $1 \square$ & $\mathbf{2} \square$ & $\mathbf{3} \square$ & $\mathbf{4} \square$ & $\mathbf{5} \square$ \\
\hline Demonstration of relevant Continuing Education that ensures their prescribing skills are kept to date & $1 \square$ & $\mathbf{2} \square$ & $\mathbf{3} \square$ & $\mathbf{4} \square$ & $\mathbf{5} \square$ \\
\hline $\begin{array}{l}\text { Specializing in clinical areas that conform with additional prescribing rights assumed (eg. Diabetes, Cardiology, } \\
\text { Asthma, Anticoagulation, Pain management, Infections) }\end{array}$ & $1 \square$ & $2 \square$ & $3 \square$ & $4 \square$ & $5 \square$ \\
\hline Specialist registration as presribers with the registering body & $1 \square$ & $2 \square$ & $3 \square$ & $4 \square$ & $5 \square$ \\
\hline Other, (please specify): & $1 \square$ & $2 \square$ & $3 \square$ & $4 \square$ & $5 \square$ \\
\hline
\end{tabular}




\begin{tabular}{|l|l|l|l|l|l|}
\hline I believe additional IT resources in the Pharmacy would be needed to support pharmacist prescribing & $1 \square$ & $2 \square$ & $3 \square$ & $4 \square$ & $5 \square$ \\
\hline I believe I have access to sufficient patient information in order to make prescribing decisions for them & $1 \square$ & $2 \square$ & $3 \square$ & $4 \square$ & $5 \square$ \\
\hline I believe prescribing and dispensing should be carried out in separate areas in the Pharmacy & $1 \square$ & $2 \square$ & $3 \square$ & $4 \square$ & $5 \square$ \\
\hline I believe a separate quiet consulting area for pharmacist prescribing should be created in the Pharmacy & $1 \square$ & $2 \square$ & $3 \square$ & $4 \square$ & $5 \square$ \\
\hline I believe current staff arrangements in the Pharmacy can support expanded pharmacist prescribing & $1 \square$ & $2 \square$ & $3 \square$ & $4 \square$ & $5 \square$ \\
\hline I believe independent prescribing by a pharmacist should NOT occur in a community pharmacy (excluding S3's) & $1 \square$ & $2 \square$ & $3 \square$ & $4 \square$ & $5 \square$ \\
\hline
\end{tabular}
$1=$ strongly disagree; $2=$ disagree; $3=$ neutral; $4=$ agree; $5=$ strongly agree

9) In relation to the extension of pharmacists'current roles in the management of minor ailments:

a)

I believe a more defined consultation system should be set up for provision of Pharmacist Only Medicines (i.e. S3's)

I believe such a defined consultation system would require a separate consultation room and possibility for customers to make appointments with the pharmacist in regards to minor ailments I believe that any extension of current role in the management of minor ailments would require remuneration I believe medicines prescribed from an expanded role and consultations should be claimable from Medicare I believe current staff arrangements in the Pharmacy can support an expanded pharmacist' s role in the management of minor ailments

\begin{tabular}{|l|l|l|l|l|}
\hline $1 \square$ & $2 \square$ & $3 \square$ & $4 \square$ & $5 \square$ \\
\hline $1 \square$ & $2 \square$ & $3 \square$ & $4 \square$ & $5 \square$ \\
\hline $1 \square$ & $2 \square$ & $3 \square$ & $4 \square$ & $5 \square$ \\
\hline $1 \square$ & $2 \square$ & $3 \square$ & $4 \square$ & $5 \square$ \\
\hline $1 \square$ & $2 \square$ & $3 \square$ & $4 \square$ & $5 \square$ \\
\hline
\end{tabular}

b) I believe that the time required for such a consultation would have to be: 3 minutes $\square, 5$ minutes $\square, 10$ minutes $\square$

c) I believe that Pharmacist remuneration (excluding medication cost) for such a service would have to be: $\$$ per consultation (please specify amount)

10) Please provide us with some further demographics information

- A)Gender: M $\square \quad F \quad \square \quad$ Age:_years

- B)How many years have you been registered as a Pharmacist:__ years

- C)Do you own a Pharmacy: YES

NO $\square$

- D)Where do you practice:

- $\quad$ Western Australia $\square$; NSW $\square$; vIC $\square$; QLD $\square$; SA $\square$;TAS $\square$; ACT $\square$; NT $\square$.

- Overseas $\square \quad$ (Please specify the country:

- E) Where do you work? Community $\square \quad$ Hospital $\square \quad$ Medication Reviews $\square \quad$ Other

- F) Please provide Pharmacy or work location postcode

- G) If you work in community Pharmacy please indicate its size of operation: small $\square$ (turnover $<\$ 2 \mathrm{~m}$ ); large $\square$ (turnover $>\$ 2 \mathrm{~m}$ )

- H)Telephone contact: (OPTIONAL)

Please feel free to contribute to this project by adding your personal comments on important factors for consideration related to pharmacist prescribing, which have not been addressed in this questionnaire:

\section{THANK YOU VERY MUCH FOR YOUR TIME IN PARTICIPATING IN THIS SURVEY}

Please ensure no answers have been left out as due to the nature of statistical data analysis applied, missing responses can lead to exclusion of your valuable information 